\title{
CHAIRS: THE AMBIGUITY OF INVISIBLE OBJECTS
}

\author{
Salvatore Fiore \\ School of Computing and I.T, University of Wolverhampton, U.K.
}

Abstract: In this paper, I describe work oriented to better understanding meaningmaking within the experiences of blind people. Based on pragmatist aesthetics, the work presented forms part of an extended project towards the development of an interactive chair designed in light of specific ways in which blind people construct meaningful experiences around interactive artefacts. This paper discusses one phase of the research leading up to the construction of the chair that has involved the use of storytelling as an imaginative means of exploring interaction possibilities and experiential quality. The work is aimed at fostering an approach that prioritises designer agency and supports a connection between the different ways of experiencing of a sighted designer and blind users of the artefact. A story is presented and conclusions are drawn for the continuing work.

Key words: design, interactivity, storytelling.

\section{INTRODUCTION}

Human Computer Interaction (HCI) approaches have traditionally been guided by criteria of measurability of success in supporting human-object interactions, simplification and representation of human and machine behaviours and predictability. People and interaction are modelled in terms of processes and tasks, establish practices that provide for the design of highly efficient, usable and transparent systems. However, recent developments in HCI research concerned with establishing theory and practice that instead take human experiencing as both object and ideation are bringing alternative conceptions of possible approaches to the creation of 
technological artefacts. Recently, many HCI researchers concerned with experience have turned towards various interdisciplinary paradigms and metaphors, as diverse as Literary Theory (McCarthy \& Wright, 2003) (Coyne \& Rebelo, 2003), Art (Gaver et al, 2004) and Pragmatist Aesthetics (Petersen et al, 2004) (Fiore, 2003; 2004) (McCarthy and Wright, 2004a; 2004b) for ideation.

The contribution of Pragmatist Aesthetics to such recent advancements in HCI is particularly noteworthy for providing a way of understanding experience in an holistic way. Pragmatism, and particularly the works of John Dewey (Dewey, 1933; 1938; 1958), accounts for the socio-historical, intellectual, physical and emotional dimensions of experience that work together to give an experience its unique and unrepeatable quality. Taking such a standpoint, Petersen et al (2004) emphasise equally the socio-cultural nature of artefacts, whereby the aesthetic is "released in dialogue as we experience the world...based on valuable use relations influencing the construction of our everyday life" (p.271), the inseparability of body and mind in meaning-making that contrasts the preoccupations with separating humans into body and mind of dualist perspectives, and instrumentality that links with the notion that for a thing to have value, for it to have the potential to deeply move and provoke a person toward new insight, it must relate to human needs, desires, fears and hopes. In this sense, artefacts achieve meaningfulness through their appropriation in use. Such issues are also emphasised in McCarthy and Wright (2004b) and Fiore (2003a; 2003b; 2004). Such approaches avoid the ad hoc combining of complementary ideologies and instead adopt Pragmatism as an entire alternative perspective on experience, subverting an analytical understanding of computing systems.

However, if this perspective is to foster tangible objects for $\mathrm{HCI}$, more research is needed to examine new modes of practice that support such an holistic understanding of experience. In particular, pragmatist $\mathrm{HCI}$ needs to develop methods that account for experience as a phenomenon relevant equally to the creation of artefacts as to their ongoing use and appropriation as meaningful objects into the lives of people. This rests on a notion of the 'designer' not as neutral observer, but as an active, emotional agentive individual in the construction of objects, that will inevitably form the focus for reflective experiences. Dewey's conception aesthetic experience necessitates viewing designers as collaborative agentive subjects, who create through their own reflection and phenomenological being. The object is an expression of the designer's perspective and mirrors their way of seeing the world so that the act of designing becomes itself a means of reflection in and on experience. According to Dewey, we are always seeking to resolve conflict, doubt, and indeterminateness into harmony, employing the emotional-volitional aspects of experiencing as processes of sense-making. 
Design might be viewed in this sense as an endeavour that is closer to art than craft, whereby, as Collingwood describes, the goal is not to fabricate a planned emotional effect on others but rather for the artist "...to explore his own emotions; to discover emotions in himself of which he was unaware, and, by permitting the audience to witness the discovery, enable them to make a similar discovery about themselves..." (Collingwood, 1958, p.119). The question then is how HCI might provide methods that support creative subjects in establishing practices to connect to their audience.

\section{CREATING INVISIBLE OBJECTS}

Despite the pragmatist turn towards experience in $\mathrm{HCI}$, such concerns generally fail to address the particular needs of blind users of technologies, as well as people disabled in other ways. The danger with this is that regardless of the quality and integrity of the research, accessibility may be relegated to the status of a secondary add-on in the design process, involving the functional adaptation of technologies that are really designed with the sense-making processes of sighted people in mind.

From a Pragmatist perspective, it becomes necessary to accept the unique qualities brought to each experience by the subject, their way of perceiving the world as a sensing, conscious being. This raises particular problems for the case of sighted designers aiming to design artefacts that will be meaningful for others who are blind.

Josselson argues for empathy and narrative as "routes to imagining what is real in whole people in their world" (Josselson, 1995, p.29), suggesting that we must first recognise our own role as knower before we can know the real, internalising our observations in the external world so that we might 'tell a story about what we believe we know' (ibid). She suggests the possibility to advocate an 'empathic stance' within research which focuses on discovery rather that the confirmation of hypotheses or the pursuit of illusory pre-existing truths; "If we listen well, we will unearth what we did not expect. This becomes the paradigm for discovery" (ibid, p. 30). Might not HCI therefore be enriched by methods that support designers in using imagination and empathy to understand something about the way others experience the world differently. To this end, we seek new conceptions of approaches to the creation of objects that suggest meaningful possibilities for interaction for a blind user and help deepen or broaden the objective conditions open to that person to experience in their way. 


\section{THE RESEARCH}

The aim of this research is to further explore these issues with a particular focus on the ambiguity of an interactive object as experienced with or without sight. The main work focuses on the creation of a chair, the qualities of which emerge from the researcher's explorations into the blind perspectives on the world.

As a starting point, various autobiographies by blind people have been examined. Such literary study did not aim to find evidence of specific prescribed hypotheses about blind experience. Instead, the activity was one of allowing relevant issues to be revealed in the reading as I related the texts to my own experiences as a sighted person. A discussion of this work is presented elsewhere (Fiore, Wright \& Edwards, 2005).

As a means of reflecting further on the issues emerging through the autobiography readings, I have adopted storytelling as a way of realising imaginative reflections on the experiences of others, in object form. The story presented below was composed as a way of exploration of my own reflections on the life stories embraced as documents of experience. It is not intended to be read as a realistic contrivance aimed at summarising qualities of blind experience into manageable 'key issues' which would be demonstrative of an analytical approach. It is an effort to try to imagine through experiences of blindness as understood dialogically in the reading of the texts of others, opening a phase of active reflection following the reading. The focus as such is on felt experience as opposed to actions or tasks.

The document is essentially the narrative of a sighted person purposefully trying to imagine a world without sight. It connects the two ways of being, so that one might design an object that has the potential to be meaningful to the other.

The story will form the basis for the subsequent stage of the research, which involves the development of a storyboard continuation, aimed at further exploring the object and interaction possibilities. This will further guide the construction of the interactive chair itself. Significantly, the chair itself is not intended as a solution to a problem, but as an object created through exploration that will itself further explore the ambiguities of objects and the particularities of interactions between blind people and the objects that inhabit their world. 


\section{A STORY ABOUT A CHAIR:}

"In the distance, the feint sound of traffic was a buzz in the air, a gentle hum that floated freely over the crystal coated grass, enveloping the open space in sound and yet failing to contain it, continuing its fading stream. The soft breeze carried the clean smells of frozen earth and chestnuts. A cold sun hung white in the cobalt sky, suspended like a distant bulb, its heat a distant memory. Footsteps crunched over the green as the early crowd criss-crossed the space, making towards objects of their desire, ready to bargain or only bemuse. Anna moved cautiously through the emptiness of the open space. To her, the stillness of the air made the field seem as infinite as the sky. Moving towards people, she could hear their conversation already: a man and a woman, talking of some object, reminiscing in shared experiences of a now extinct relic of their childhoods. The woman's voice suddenly seemed to rise, not in volume, but physically lift upward; she had stood up. As other people passed by, Anna caught fragments of their conversation. She turned her attention to her daughter, Katie, who walked steadily and reliably between Anna and her husband Michael, one guiding hand for each. The child led them towards the reminiscing couple, steering her parents skilfully towards items worth exploring at the car boot sale. Anna's guide dog, Lucy, had been given the Sunday off and trotted excitedly on a lead at her left. Michael carried a long white cane to feel his way and rested his other hand lightly on his daughter's shoulder. The family moved silently and trustingly together. They had come early to avoid the chaos around the parked cars and tables.

It took exactly 36 steps to reach the chosen stall. The man and woman had now stopped talking and while he settled curios on a tarpaulin spread over the ground, she returned to her seat to sip hot coffee. As Anna and her family stopped and greeted the woman, the young girl left her mother's hold, returning seconds later with a box carved all over in intricate detail that bewildered even Anna's expert fingers. It smelt like a church; the delicate mingling of petals and aged oak. The family had just moved into a new house. The box would be perfect on the table that stood four steps inside the hallway from the front door. Anna would keep her keys there and the small everyday objects that always seemed to disappear from their carefully rehearsed setting.

Agreeing a price for the box with the woman, Anna turned her attention to the other object they needed for that same place; a chair. The woman indicated the three she had to choose from, but one was exceptional and an immediate choice. The woman recounted the story of the chair; how her grandfather had carved it as a gift for his wife. The cushions she had stitched herself, dressing the naked object, adding herself to its romantic history. Her 
pride at its artistry was clear and she seemed reluctant to sell the chair. She showed Anna the silkiness of the sculpted wood and invited her to sit. This was an ideal chair for their hallway - comfortable, just the right height for the telephone table and, according to sighted bystanders, very elegant in appearance too. It would serve its purpose well.

The next day, Anna awakes disorientated in the new house. After just a few days, she still struggles to remember the position of everything and the first moments of the day gift her with a new bruise on her leg from a forgotten tea-chest, still packed with belongings and minutes lost gathering together her clothes. It is Monday morning and she is late and frustratingly slow preparing her daughter for school. After her husband and daughter have left, she settles down at the computer to start work. After concentrating on a decidedly one-way conversation with the screen-reader for some hours, Anna decides it is time for shopping. She calls Lucy and goes to the hallway to fetch down the dog's guide harness. And there she stops in her tracks. As she enters the hall, she can hear a vibrating sound ahead of her.

Thinking that her mobile phone has been erroneously switched to silent vibrate, she rushes to the table, searching for the juddering object but finding nothing except the box from the car boot sale. It is not the phone vibrating. Following the noise, Anna moves towards the new chair. As she approaches, the vibration seems to intensify and quicken. Lucy barks once at the convulsing thing in protest and confusion. All sorts of thoughts are going through Anna's mind now. Is it a joke? Is it magic? Is it dangerous.... an electrical fault of some kind? What should she do? Why is the chair vibrating? Should she sit? Growing anxious, she eventually sits, and as she does, the vibration ceases. Anna stays motionless. Now she dare not move, unsure of what will happen next. When nothing does, Anna grows restless, wanting to get up and leave. With a rush of confidence, she leaps out, bounding away and stubbing her toe on the table that sits innocently silently and clumsily - nearby. What is the meaning of this strange chair? Anna picks up the dog harness from the table where she left it. She is oddly nervous to touch even the table: the things around her suddenly seeming so much more unpredictable and unknown. Then she realises that the chair has been silent and still. It does not intrude on any of her four senses as she retreats to the kitchen for a glass of water and time to think.

After some moments, she begins to see some humour in the situation and laughs (a little nervously) out loud to herself. But when she re-enters the hallway, the chair starts up its lunatic dance again. Intrigued now, she begins to play with it, moving closer and retreating; the chair crescendos and subsides. But she is not sure whether she or the chair is really in control. It is predictable now, but she cannot stop it without sitting down. It knows when 
she is coming and tells her than it knows. She cannot ignore its presence and it dominates the space it occupies like a territorial animal.

Realising that time has been passing during her chair games, Anna exits hurriedly with her dog, the vibrations fading behind her. When she returns, her husband and daughter are already at home. Unsure of what she will find and not prepared to try and explain the strange happenings of the afternoon to them, she enters timidly. The chair is silent. Could it have been a dream? Worse still, could she be developing some unknown hearing disorder in addition to her blindness? No, she reasons; she could feel it too. She moves slowly towards the position of the chair, reaching out to touch it, half expecting it not to be there at all. When she finds it, something is different. Feeling properly, she recognises the fabric of her daughter's coat strewn over the chair. The child has tricked the creature into silence!

Anna hears her daughter emerge skipping and Katie rushes to kiss her mother. Without a word, she pulls off her coat from the chair and almost instantaneously, steps confidently up onto it to reach and hook the coat onto a peg. Anna grasps onto her daughter's waist, worried that the chair will 'wake up' and shake her onto the floor. But it is still. Then, as soon Katie steps down, the chair, seemingly feeling ambushed, shakes madly in the sudden proximity of mother and child. "You have to sit." says Katie matterof-factly, "It's telling you, you can sit". Anna doesn't quite know how to respond. "Don't be silly. Chairs can't tell you things" and then with suspicion "How do you know its saying that?". For the child, the wisdom to suggest the impossibility of a communicative, even helpful chair, was lacking. She imagined the chair to be friendly and helpful (if a little insistent). "Daddy said if they had one like that at work, then he wouldn't need his cane to find his desk any more. The chair could show him the way to it". This bewildered Anna further; could her husband also believe this fantasy of a 'living' chair?

Over the next few days, Anna's feelings of distrust and uncertainty towards the chair began to dissipate. She stopped wondering about the secret mechanism causing the chair to vibrate and accepted its presence. She even began to enjoy it. She had come to enjoy sitting on the chair when 'invited' and would sit talking on the phone there. Spending time with the chair, she had even come to learn new possibilities with it. Most interestingly, she discovered that the chair would indicate the presence of another person to her: there she would be sitting when a warmth would radiate from the seat, accompanied by an almost imperceptible tremble. As the person drew nearer, she found herself feeling less surprised by their sudden emergence out of nowhere and more prepared to try to recognise them before they spoke to her. Sitting in that chair, the element of surprise that her blindness 
forced upon her in everyday encounters, was diminished. The space around her seemed mapped by the radiant sense of the chair.

For some weeks, Katie's friends would play around the chair, teasing it, trying to creep up on it unnoticed and delighting in it's sudden convulsions when they were 'discovered'. But they soon grew tired of the predictable object and moved on to new and different toys. Anna, however, began to have new ideas about the chair. She could not forget her husband's comments about using the chair at work and one day suggested that he ask his brother to take it there for him to use.

The first few days that Michael had the chair at his desk, his colleagues found the whole thing amusing. They jostled to try and see how it worked and invented jokes about this new lively thing. Before long however, they began to feel quite differently about it. When they approached Michael, he now knew that they were coming without the need to speak. It was 'seeing' their approach for him. The biggest changes were for Michael though. It was a sense of control and freedom. He came to know it's signals subtly. Sitting there, he could feel the hesitancy in the approach of an indecisive colleague or the speed of an eager friend, coming over to talk. It was something like the signals Anna had told him she felt from Lucy the guide dog; she knew when the animal was reluctant or confident from the tiny changes in the position of the harness and the speed of her gait. In the sometimes noisy office, the chair helped Michael feel more at home in his surrounding space. It gave him back some unexplainable quality of the sense he had lost all those years before. The difference was small, but for Michael, it was so very important. He thanked Anna for this gift."

\section{CONCLUSIONS}

Writing the story was a means of reflection that brought some issues to the fore, which might otherwise have been lost through an analytical approach. The exercise was one of exploration for the designer to work imaginatively to consider the implications and interaction possibilities of such an object for a blind person. The focus was not on setting specifications or extracting requirements from intended 'users' but on exploring the nature of experience and the place of certain artefacts in the shaping of aesthetic experiences of blind people in everyday situations.

\section{REFERENCES}

Brace, M. (1980) Where there's a will. Souvenir Press 
Coyne, R. (1999) Technoromanticism: Digital Narrative, Holism, and the Romance of the Real. MIT Press.

Coyne, R. and Rebelo, P. (2003) Resisting the Seamless Interface. HCI, Arts \& Humanities workshop, University of York

Dewey, J. (1958) Art as Experience. Capricorn.

Dewey, J. (1938) Experience and Education. Macmillan.

Dewey, J. (1933) How we think. D.C. Heath and Company.

Dourish, P. (2001) Where the Action is: The Foundations of Embodied Interaction. MIT Press.

Dunne, A. \& Raby, F. (2001) Design Noir: The Secret Life of Electronic Objects. Birkhäuser.

Fiore, S. Wright, P. \& Edwards, A. (2005) Agency, interaction and disability: Making sense through autobiographical accounts. Proc. Include 2005.

Fiore, S. (2004) From Designing for Function to Designing for Meaning. Proc. ECCE-12.

Fiore, S. (2003a) Supporting design for Aesthetic Experience. HCI, Arts \& Humanities workshop, University of York.

Gaver, W., Boucher, A., Pennington, S. and Walker, B. (2004) Evaluating Technologies for Ludic Engagement. Available at http://www.cs.cornell.edu/people/sengers/ReflectiveHCI /proceedings.html.

Harrison, S. and Dourish, P. (1996) Re-Place-ing Space: The Roles of Place and Space in Collaborative Systems. In Proc. CSCW'96, pp.67-76. ACM.

Hocken, S. (1988) Emma and I. Time Warner.

Hull, J. M. (1991) Touching the Rock: An experience of blindness. Arrow.

Josselson, R. (1995) Imagining the Real: Empathy, Narrative, and the Dialogic Self. In Josselson, R. and Lieblich, A. (eds.) Interpreting Experience: The Narrative Study of Lives (vol. 3). Sage Publications. Keller, H. (1996) The Story of My Life. Dover Publications.

Kuusisto, S. (1998) Planet of the Blind. Faber and Faber.

Magee, B. \& Milligan, M. (1995) On Blindness: An exchange of letters. Oxford Univ. Press.

McCarthy, and Wright, P. C. (2004a) Technology as Experience, MIT Press.

McCarthy, J and Wright, P. (2004b) Putting 'Felt-life' at the centre of HCI. Proc. ECCE-12.

Petersen, M. G., Iversen, O. S., Krogh, P. G. \& Ludvigsen, M. (2004) Aesthetic Interaction A Pragmatist's Aesthetics of Interactive Systems. In Proc. DIS2004. 